\title{
The natural history of inflammatory bowel disease and primary sclerosing cholangitis after liver transplantation - a single-centre experience
}

\author{
Karli J Moncrief $\mathrm{MSc}^{1}$, Anamaria Savu PhD², Mang M Ma MDㄹ, Vince G Bain MD¹, \\ Winnie W Wong MD¹, Puneeta Tandon MD
}

\begin{abstract}
KJ Moncrief, A Savu, MM Ma, VG Bain, WW Wong, P Tandon. The natural history of inflammatory bowel disease and primary sclerosing cholangitis after liver transplantation - a single-centre experience. Can J Gastroenterol 2010;24(1):40-46.
\end{abstract}

OBJECTIVE: To describe the natural history of primary sclerosing cholangitis (PSC) and inflammatory bowel disease (IBD) after liver transplant, the predictors of PSC and IBD recurrence, and the interaction of these disease processes.

METHODS: Data regarding patients who received liver transplants for PSC at the University of Alberta Hospital (Edmonton, Alberta) from 1989 to 2006 were retrospectively reviewed. Recurrent PSC (rPSC) was defined by the Mayo Clinic criteria. Cox proportional hazards modelling and Kaplan-Meier statistics were used.

RESULTS: Fifty-nine patients were studied, with a median follow-up of 68 months. A total of $71.2 \%$ of patients were diagnosed with IBD pretransplant. Clinical IBD severity post-transplant compared with severity pretransplant was unchanged in $67 \%$, worse in $26.5 \%$ and improved in $6.1 \%$ of patients. Twenty-five per cent of patients developed rPSC posttransplant. The occurrence of at least one episode of acute cellular rejection (hazard ratio 5.7; 95\% CI 1.3 to 25.8) and cytomegalovirus mismatch (hazard ratio $4.2 ; 95 \%$ CI 1.1 to 15.4 ) were found to be significant predictors of rPSC. Although not statistically significant, there was no rPSC in patients without pre- or post-transplant IBD, and in only one patient with a colectomy. Actuarial patient survival rates at one, five and 10 years posttransplant were $97 \%, 86 \%$ and $79 \%$, respectively. Although a significant proportion of patients experienced worsening IBD post-transplantation, the presence or severity of IBD did not influence rPSC or patient survival.

CONCLUSION: Acute cellular rejection and cytomegalovirus mismatch were both identified as independent predictors of rPSC. The impact of steroids and the ideal immunosuppressive regimen for the control of both IBD and PSC post-transplant requires further examination in prospective studies.

Key Words: Inflammatory bowel disease; Liver transplantation; Primary sclerosing cholangitis; PSC; Recurrent PSC

$\mathrm{P}$ rimary sclerosing cholangitis (PSC) is a progressive, cholestatic liver disease of unknown etiology, characterized by inflammation and fibrosis of the biliary tree. Liver transplantation remains the treatment of choice for end-stage PSC and accounts for approximately $6 \%$ to $10 \%$ of transplants in North America (1-4).

Transplantation is associated with excellent patient outcomes, with survival rates of up to $90 \%$ and $85 \%$, and graft survival of $82 \%$ and $72 \%$ at one- and five-years posttransplantation, respectively $(5,6)$. Despite a reasonably good prognosis following transplantation, the post-transplant course of PSC patients may be complicated by the recurrence of PSC (rPSC) in the allograft (7-9) as well as by worsening
L'évolution naturelle des maladies inflammatoires de l'intestin et de la cholangite sclérosante primaire après une greffe du foie : L'expérience d'un seul centre

OBJECTIF : Décrire l'évolution naturelle de la cholangite sclérosante primaire (CSP) et des maladies inflammatoires de l'intestin (MII) après une greffe du foie, les prédicteurs de CSP et de récurrence de MII et l'interaction entre ces processus morbides.

MÉTHODOLOGIE : On a procédé à l'analyse rétrospective des données portant sur les patients qui avaient subi une greffe du foie en raison d'une CSP au University of Alberta Hospital d'Edmonton, en Alberta, entre 1986 et 2006. On a défini la CSP récurrente (CSPr) d'après les critères de la clinique Mayo. On a utilisé le modèle de hasards proportionnels de Cox et les statistiques de Kaplan-Meier.

RÉSULTATS : On a étudié 59 patients qui avaient profité d'un suivi médian de 68 mois. Au total, 71,2\% patients étaient atteints d'une MII diagnostiquée avant la greffe. La gravité clinique de la MII après la greffe par rapport à celle avant la greffe était demeurée inchangée chez $67 \%$ des patients, avait empiré chez $26,5 \%$ des patients et s'était améliorée chez $6,1 \%$ des patients. Vingt-cinq pour cent des patients ont présenté une CSPr après la greffe. On a déterminé que l'occurrence d'au moins un épisode de rejet cellulaire aigu (ratio de risque de 5,7; 95 \% IC 1,3 à 25,8) et de mésappariement du cytomégalovirus (ratio de risque de 4,2; 95 \% IC 1,1 à 15,4) étaient d'importants prédicteurs de CSPr. Même si cette observation n'est pas statistiquement significative, on n'observait pas de CSPr chez les patients sans MII avant ou après la greffe, et on l'a constatée chez un seul patient ayant subi une colectomie. Les taux de survie actuariels des patients un an, cinq ans et dix ans après la greffe s'élevaient à $97 \%, 86 \%$ et $79 \%$, respectivement. Même si une forte proportion des patients ont souffert d'une aggravation de leur MII après la greffe, la présence ou la gravité de la MII n'a pas influé sur la CSPr ou sur la survie. CONCLUSION : On a constaté qu'un rejet cellulaire aigu et un mésappariement du cytomégalovirus étaient tous deux des prédicteurs indépendants de CSPr. Un examen plus approfondi des effets des stéroïdes et de la posologie immunosuppressive idéale pour le contrôle de la MII et de la CSP après la greffe s'impose, dans le cadre d'études prospectives.

inflammatory bowel disease (IBD). The natural history of post-transplant rPSC (in the context of IBD), the impact of immunosuppressive therapy and other risk factors associated with these conditions remain controversial. Until recently, there were no studies that evaluated all of these factors in a single cohort of patients. Accordingly, the present study aimed to describe the natural history of IBD post-transplantation, the predictors of severe IBD post-transplantation (including the impact of different immunosuppressive regimens), the natural history of PSC post-transplantation and the predictors of rPSC (including the impact of different immunosuppressive regimens, IBD activity and the use of marginal donor allografts on recurrence).

${ }^{1}$ Department of Medicine; ${ }^{2}$ Department of Public Health Sciences, University of Alberta, Edmonton, Alberta

Correspondence: Dr Puneeta Tandon, Department of Medicine, University of Alberta, 130 University Campus, Edmonton, Alberta T6G $2 X 8$.

Telephone 780-492-9845, fax 780-492-9873, e-mail ptandon@ualberta.ca

Received for publication September 24, 2008. Accepted February 8, 2009 


\section{METHODS}

\section{Patients}

The present study was a retrospective analysis of all patients transplanted for PSC from 1989 to 2006, at the University of Alberta Hospital (Edmonton, Alberta). Data were collected with approval from the University of Alberta's Health Research Ethics Board (Study 6894). Inclusion criteria were a pretransplant diagnosis of PSC established by consistent laboratory, radiological and/or histological findings. The diagnosis was confirmed by compatible explant pathology. Exclusion criteria were age younger than 18 years, blood type $\mathrm{ABO}$ incompatible transplants, hepatocellular carcinoma, graft loss within two months post-transplant not related to rPSC and lack of follow-up information. In the case of graft loss within two months after transplant, the patient's second graft was considered for data analysis. Data were collected from the electronic organ transplant tracking record database and patient medical records.

Demographic and clinical data recorded for each patient included sex, age at transplant, length of follow-up, age at diagnosis and method of diagnosis of PSC; pre- and post-transplant medications, presence of IBD (including age at diagnosis and method of diagnosis, pre- and post-transplant severity, and extent of disease and presence of an intact colon before and after transplant), patient status at transplant (including Model for End-Stage Liver Disease score and Child-Pugh class, characteristics of transplant, including transplant type, ABO mismatch and cytomegalovirus [CMV] mismatch), outcomes of transplant (including graft and patient survival, recurrence of PSC and time to recurrence), and immunosuppressive regimen and number of biopsy-proven rejection episodes.

rPSC was defined according to established criteria previously published (10), which requires cholangiographic and/ or histological evidence of biliary stricturing, or fibrosis in the strict absence of other potential causes of biliary stricturing (eg, hepatic artery thrombosis/stenosis, established ductopenic rejection, anastomotic strictures alone, nonanastomotic strictures before post-transplantation day 90 and $\mathrm{ABO}$ incompatibility). Because the centre does not perform protocol liver biopsies, the initial suspicion of rPSC was often based on the presence of abnormal liver enzyme levels. The diagnosis of acute cellular rejection (ACR) was confirmed by biopsy and was based on the established Banff criteria (11). Categorization of IBD severity both pre- and post-transplantation was modified from Befeler et al (12), in which mild disease refers to quiescent disease or disease controlled with aminosalicylates (eg, 5-aminosalicylic acid [5-ASA]), and severe disease refers to at least two flares requiring corticosteroid therapy, one difficultto-control flare or patients requiring colectomy. All available data were considered in the determination of disease severity. Marginal donor allografts were arbitrarily defined as donors with two or more of the following extended donor criteria: donor older than 60 years of age $(13,14)$, donor body mass index greater than $30 \mathrm{~kg} / \mathrm{m}^{2}(13-15)$, hepatic steatosis greater than $30 \%$, cold ischemic time longer than $12 \mathrm{~h}(14,15)$, high-dose vasopressors pretransplant (noradrenaline greater than $0.2 \mu \mathrm{g} / \mathrm{kg} / \mathrm{min}$ or dobutamine greater than $6 \mu \mathrm{g} / \mathrm{kg} / \mathrm{min}$ ) (14), or donor aspartate aminotransferase or alanine aminotransferase levels greater than three times normal (15).

Post-transplant immunosuppression varied over the course of the study, ranging from a calcineurin inhibitor (cyclosporine or tacrolimus) to an antimetabolite (azathioprine or mycophenolate mofetil), with or without prednisone. Sirolimus was used in patients with hepatocellular carcinoma or calcineurin toxicity. According to the program's protocol, ACR was treated with a tapered corticosteroid regimen. In cases of nonresponse to an initial steroid trial, a second tapering corticosteroid regimen was administered, followed by antilymphocyte antibody therapy if necessary.

\section{Statistical methods}

Descriptive statistics including median and interquartile range for demographic variables and clinical characteristics were tabulated for all transplanted patients, transplanted patients who recurred and transplanted patients who did not recur during the follow-up time. The cumulative incidence of rPSC after transplantation was calculated using death as a competing risk event and was graphically summarized. To determine predictors of survival from transplantation to rPSC, Cox proportional hazards models (16) were used, from which hazard ratios (HR) and 95\% CIs were estimated. A multivariable Cox model that included all variables with $\mathrm{P}<0.20$ in the univariate analysis was constructed (16). Pre- and post-transplant IBD severities were compared using a conditional symmetry model for matched-pairs data (17), with severity scaled into three ordered categories: no disease, mild disease and severe disease. Patients who underwent colectomy before transplantation were excluded from the comparison. To identify factors associated with severe IBD in patients without pretransplant colectomy and who experienced IBD post-transplant, univariate and multivariate logistic regression analyses were performed. Results are presented as ORs with 95\% CIs. The Kaplan-Meier method was used to estimate survival from the time of transplantation to death. The impact of rPSC on survival was investigated using Cox regression, with rPSC treated as a time-varying covariate. All data were analyzed using SAS version 9.1 (SAS Institute Inc, USA) and R version 2.5.1.

\section{Baseline characteristics}

\section{RESULTS}

From October 1989 to November 2006, 68 liver transplantations for end-stage PSC were performed at the University of Alberta Hospital. Of these, 59 patients transplanted for established PSC were included in the present retrospective review, four patients were excluded due to minimal follow-up information and five were excluded due to pediatric status at the time of transplant. Four of 59 patients lost their initial grafts within two months due to hepatic artery thrombosis $(n=3)$ or hepatic ischemia not related to hepatic artery thrombosis $(n=1)$ and, therefore, their second grafts were considered for the purposes of the study. Pertinent baseline demographic and clinical characteristics are summarized in Table 1 . The median follow-up was 68 months (range 33 to 106 months). Median age at transplant was 46 years (range 37 to 53 years) and $78 \%$ of the study population were men (Table 1). A total of 42 patients $(71.2 \%)$ were diagnosed with IBD before transplantation, of whom $81 \%$ had ulcerative colitis (UC). Disease activity was mild in 24 patients (57.1\%), and severe in 18 (42.9\%). A total of 10 patients $(16.9 \%)$ underwent colectomy before transplantation. Cholangiocarcinoma was discovered in two 


\begin{tabular}{|c|c|}
\hline \multicolumn{2}{|l|}{ Patient characteristics } \\
\hline Men/women, n/n & $46 / 13$ \\
\hline Age at transplantation, years (median [IQR]) & $46(37-53)$ \\
\hline Follow-up after liver transplantation, months (median [IQR]) & $68(33-106)$ \\
\hline Age at diagnosis of PSC, years (median [IQR]) & $38(29-47)$ \\
\hline \multicolumn{2}{|l|}{ Child-Pugh class at transplant, $\mathrm{n}(\%)$} \\
\hline A & $6(10.2)$ \\
\hline B & $36(61.0)$ \\
\hline C & $17(28.8)$ \\
\hline MELD score at transplant, median (IQR) & $14(10-20.5)$ \\
\hline Live donor recipient, n (\%) & $4(6.8)$ \\
\hline Cytomegalovirus mismatch recipient, $\mathrm{n}(\%)$ & $20(33.9)$ \\
\hline Cholangiocarcinoma in explant, $\mathrm{n}(\%)$ & $2(3.4)$ \\
\hline Presence of IBD, $\mathrm{n}(\%)$ & $42(71.2)$ \\
\hline Ulcerative colitis, $n$ & 32 \\
\hline Crohn's colitis, $n$ & 8 \\
\hline Indeterminate colitis, $\mathrm{n}$ & 2 \\
\hline Duration of IBD before transplant, years (median [IQR]) & $13(10-20)$ \\
\hline \multicolumn{2}{|l|}{ Pretransplant IBD course, $\mathrm{n}$ (\% IBD patients) } \\
\hline Mild disease & $24(57.1)$ \\
\hline Severe disease & $18(42.9)$ \\
\hline Presence of an intact colon before transplantation, $\mathrm{n}(\%)$ & $49(83.1)$ \\
\hline
\end{tabular}

IBD Inflammatory bowel disease; IQR Interquartile range; MELD Model for End-Stage Liver Disease; PSC Primary sclerosing cholangitis

(3.4\%) of the liver explants. Biliary reconstruction for 55 of the 59 transplants (93\%) was performed using a Roux-en-Y choledochojejunostomy.

\section{Course of IBD after liver transplantation}

Of the 17 patients without a pretransplant diagnosis of IBD, five $(29 \%)$ developed de novo disease at a median of 57 months (range 2 to 113 months) after transplantation. Of the 32 patients with established IBD, six (19\%) required colectomy at a median of 34 months (range 26 to 67 months) following transplantation. Indications for colectomy were active severe disease $(n=4)$, bowel perforation $(n=1)$ and colonic adenocarcinoma $(n=1)$. One patient with a history of UC more than 15 years pretransplant was diagnosed with high-grade colonic dysplasia approximately 29 months after transplantation. Despite medical advice, the patient declined early surgical intervention and developed colonic adenocarcinoma five years later, necessitating colectomy. A second patient was diagnosed with a colorectal malignancy at the end of the study follow-up.

When patients with colectomy before transplantation were excluded, IBD severity post-transplant was unchanged in $33(67 \%)$, worse in $13(26.5 \%)$ and improved in three (6.1\%) of 49 patients compared with pretransplant severity. The conditional symmetry model used to compare pre- and post-transplant IBD severity demonstrated that a significantly greater number of patients experienced worsening of IBD symptoms after transplant compared with those who improved $(\mathrm{P}=0.009)$. Patients who worsened after transplant included five who developed de novo IBD and eight patients who went from mild (quiescent disease, $n=2$; disease controlled by 5 -ASA, $\mathrm{n}=6$ ) to severe disease (flares requiring steroid therapy, $n=5$; requiring colectomy, $n=3$ ). The median time to first flare of IBD post-transplant was 14.6 months (range 3.8 to 47.6 months).

\begin{tabular}{|c|c|c|c|c|c|}
\hline \multicolumn{2}{|c|}{} & \multicolumn{2}{|c|}{ IBD severity post-transplant } & \multirow{2}{*}{ Total } \\
\cline { 2 - 5 } & No disease & Mild & Severe & \\
\hline \multirow{2}{*yyyyn}{} & No disease & 12 & 1 & 4 & 17 \\
\cline { 2 - 5 } & Mild & 0 & 16 & 8 & 24 \\
\cline { 2 - 5 } & Severe & 0 & 3 & 5 & 8 \\
\hline & Total & 12 & 20 & 17 & 49 \\
\hline
\end{tabular}

Figure 1) Pretransplant inflammatory bowel disease (IBD) severity matched with IBD severity post-transplant, $n=49(P=0.009)$

Three patients classified as improved went from requiring steroid therapy to control flares before transplant to either 5-ASAcontrolled IBD or quiescent disease after transplantation (Figure 1).

\section{Risk factors for severe IBD after liver transplantation}

Severe IBD post-transplant (ie, active disease requiring either steroid therapy or colectomy) was not related to patients' sex, age at transplant, duration and/or severity of IBD pretransplant, immunosuppression with tacrolimus versus cyclosporine or use of azathioprine post-transplant $(\mathrm{P}>0.05)$. Multivariate analysis did, however, reveal a significant protective effect of corticosteroid treatment duration on the development of severe disease post-transplant (continuous variable, OR 0.87; $95 \%$ CI 0.76 to $0.99 ; \mathrm{P}=0.04$ ) (Table 2). In a separate analysis of the same variables, no independent predictors of colectomy post-transplant were identified (data not shown).

\section{Course of PSC after liver transplantation}

Using strict criteria for diagnosis (10), 15 of 59 patients $(25 \%)$ developed rPSC following liver transplantation. Six patients had biliary complications post-transplant for reasons other than PSC. Three patients had ductopenic rejection and three patients had an anastomotic stricture alone. The cumulative incidence of rPSC, with death as a competing risk was $8 \%$ at two years, $21 \%$ at five years and $37 \%$ at 10 years. Characteristics of the patients with and without rPSC are presented in Table 3. The median time to recurrence was 40.2 months (range 19.5 to 66.1 months). Of the patients with rPSC, only one died during the course of study follow-up. His PSC recurred approximately five years after transplantation - he died from a myocardial infarction more than 13 years after transplant. A second patient with rPSC died due to recurrent disease after the study follow-up period and, therefore, was not included in the analysis. A decision was made not to relist him due to rapid rPSC in two grafts. Of the 15 patients with disease recurrence, four (27\%) received a second transplant specifically for rPSC. The median time to retransplant for these patients was 86.7 months (range 62.7 to 124.6 months). One of these patients had three transplants in total; the second transplant was performed because of ischemic injury to the first graft. While the limited number of patients with rPSC requiring retransplant $(n=4)$ precludes meaningful statistical analysis, several common clinical features were noted: male sex (four of four), age younger than 25 years at initial diagnosis of PSC (four of four), at least one episode of biopsy-proven rejection (four of four), active IBD post-transplant (four of four) and recipients of CMV mismatch allografts (three of four). 


\begin{tabular}{|c|c|c|}
\hline Variables & OR $(95 \% \mathrm{Cl})$ & $\mathbf{P}$ \\
\hline \multicolumn{3}{|l|}{ Univariate analysis } \\
\hline IBD duration pretransplant (continuous) & $1.1(0.97-1.15)$ & 0.25 \\
\hline $\begin{array}{l}\text { Corticosteroid treatment duration } \\
\text { (continuous) }\end{array}$ & $1.16(1.04-1.4)$ & 0.002 \\
\hline Presence of IBD pretransplant & $0.16(1.04-1.4)$ & 0.08 \\
\hline Use of azathioprine post-transplant & $2.25(0.6-8.7)$ & 0.2 \\
\hline Use of tacrolimus post-transplant & $0.3(0.1-1.13)$ & 0.08 \\
\hline Age at transplant (continuous) & $0.97(0.92-1.03)$ & 0.3 \\
\hline Female sex & $0.9(0.2-4.8)$ & 0.9 \\
\hline \multicolumn{3}{|l|}{ Multivariate analysis } \\
\hline $\begin{array}{l}\text { Corticosteroid treatment duration } \\
\text { (continuous) }\end{array}$ & $0.87(0.76-0.99)$ & 0.04 \\
\hline
\end{tabular}

\section{Risk factors for rPSC}

Of the potential risk factors examined (Table 4), the occurrence of at least one episode of ACR (HR 5.7; 95\% CI 1.3 to 25.8; $\mathrm{P}=0.013$ ) and CMV mismatch (HR 4.2; 95\% CI 1.1 to 15.4 ; $\mathrm{P}=0.035$ ) were found to significantly impact PSC recurrence. Although only one of 10 patients with pretransplant colectomy had rPSC after transplantation, this did not reach statistical significance as a protective factor. Similarly, although the presence of IBD before transplant did not significantly affect the development of $\operatorname{rPSC}(\mathrm{P}=0.32)$, interestingly, all patients with rPSC had confirmed IBD pre- or post-transplant. In addition to other tested variables, corticosteroid treatment duration as a continuous variable, age at transplant, pretransplant IBD severity, cyclosporine- or tacrolimus-based immunosuppression, and azathioprine- or mycophenolate mofetil-based immunosuppression did not significantly impact rPSC posttransplant $(\mathrm{P}>0.05)$.

\section{Patient and graft survival post-transplant for PSC}

Of the 59 patients who received liver transplants, 49 (83\%) are currently alive. Actuarial patient survival rates at one, two, five and 10 years post-transplant was 97\%, 95\%, 86\% and $79 \%$, respectively (Figure 2 ). Causes of death were attributed to cholangiocarcinoma $(n=2)$, sepsis $(n=3)$, coronary artery disease $(n=2)$, chronic rejection $(n=1)$, metastatic breast cancer $(n=1)$ and unknown $(n=1)$. As mentioned previously, the death from rPSC occurred after the study follow-up period and is not reflected in the results. There was no survival difference between patients with and without pretransplant IBD $(\mathrm{P}=0.17)$. Similarly, rPSC did not significantly affect patient survival (HR 0.52 ; $95 \%$ CI 0.06 to $4.49 ; \mathrm{P}=0.55$ ). Post-transplant graft survival rates at one, two, five and 10 years were $96.6 \%, 94.7 \%$, $83.6 \%$ and $67.6 \%$, respectively. When considered in a Cox regression model with PSC recurrence as a time-dependent covariate, there was no effect of rPSC on graft survival (HR 2.3; $95 \%$ CI 0.68 to $7.81 ; \mathrm{P}=0.19)$.

\section{DISCUSSION}

The outcomes of patients transplanted for PSC at our centre are consistent with outcomes in the literature. Although the severity of IBD after transplant was unchanged in the majority of patients, a significant proportion experienced exacerbation rather than improvement after transplantation. A longer
TABLE 3

Demographic and clinical characteristics of patients with and without recurrent primary sclerosing cholangitis (rPSC)

\begin{tabular}{|c|c|c|}
\hline \multirow[b]{2}{*}{ Characteristics } & \multicolumn{2}{|c|}{ Patients } \\
\hline & $\begin{array}{l}\text { With rPSC } \\
\quad(n=15)\end{array}$ & $\begin{array}{l}\text { Without rPSC } \\
(n=44)\end{array}$ \\
\hline Men/women, n/n & $13 / 2$ & $33 / 11$ \\
\hline $\begin{array}{l}\text { Age at transplantation, years } \\
\text { (median [IQR]) }\end{array}$ & $45(36-53)$ & $47(37-52)$ \\
\hline $\begin{array}{l}\text { Age at diagnosis of PSC, years } \\
\text { (median [IQR]) }\end{array}$ & $31(24-47)$ & $39(31-47)$ \\
\hline MELD score at transplant, median (IQR) & $18(13-20.5)$ & $13.5(9.8-20.8)$ \\
\hline CMV mismatch recipient & $8(53.3)$ & $12(27.3)$ \\
\hline Presence of IBD pretransplant & $11(73.3)$ & $31(70.5)$ \\
\hline $\begin{array}{l}\text { Duration of IBD before transplant, years } \\
\text { (median [IQR]) }\end{array}$ & $16(11-20)$ & $12(9.6-20)$ \\
\hline \multicolumn{3}{|l|}{ Pretransplant IBD course, n (\% IBD patients) } \\
\hline Mild disease & $7(63.6)$ & $17(54.8)$ \\
\hline Severe disease & $4(36.4)$ & $14(45.2)$ \\
\hline $\begin{array}{l}\text { Presence of an intact colon before } \\
\text { transplantation }\end{array}$ & $14(93.3)$ & $35(79.6)$ \\
\hline Pretransplant colectomy & $1(6.7)$ & $9(20.5)$ \\
\hline Presence of IBD pre- or post-transplant & $15(100.0)$ & $33(75.0)$ \\
\hline \multicolumn{3}{|c|}{ Post-transplant IBD course, n (\% IBD patients) } \\
\hline Mild disease & $5(38.5)$ & $15(62.5)$ \\
\hline Severe disease & $8(61.5)$ & $9(37.5)$ \\
\hline \multicolumn{3}{|l|}{ Maintenance immunosuppression } \\
\hline Predominantly cyclosporine & $8(53.3)$ & $14(31.8)$ \\
\hline Predominantly tacrolimus & $7(46.7)$ & $28(63.6)$ \\
\hline $\begin{array}{l}\text { Duration of steroid therapy, months } \\
\text { (median [IQR]) }\end{array}$ & $9(2-14)$ & $2.3(0-7.4)$ \\
\hline Steroid-resistant rejection & $1(6.7)$ & $2(4.5)$ \\
\hline$\geq 2$ extended donor criteria & $5(33.3)$ & $8(18.2)$ \\
\hline $\begin{array}{l}\text { Patients with } \geq 1 \text { biopsy-proven rejection } \\
\text { episodes }\end{array}$ & $11(73.3)$ & $19(43.2)$ \\
\hline
\end{tabular}

Data are presented as n (\%) unless indicated otherwise. CMV Cytomegalovirus; IBD Inflammatory bowel disease; IQR Interquartile range; MELD Model for End-Stage Liver Disease

duration of steroid use was associated with a lower rate of severe post-transplant IBD but no significant predictors of the need for post-transplant colectomy were identified. rPSC was found in 15 patients (25\%), for which CMV mismatch and at least one episode of ACR were independent predictors. Although four retransplants for rPSC were performed, survival rates exceeded $85 \%$ at five years and were unaffected by rPSC or accompanying IBD.

Although it is well-established that more than $70 \%$ of patients with PSC have underlying IBD (18-20), there is little consensus regarding the clinical course of IBD after transplantation. Several studies have demonstrated increased exacerbations of IBD despite post-transplant immunosuppressive maintenance therapy (21-25), while others have shown an unchanged or improved course $(12,26,27)$. The current study lends evidence to the view that the course of IBD either remains unchanged or is worsened after transplantation for PSC. Moreover, in the present cohort, a longer duration of steroid use post-transplant was associated with a lower rate of severe posttransplant IBD. This finding is consistent with the literature, in which retrospective studies investigating less exposure to steroids have noted worsened control of IBD post-transplant 


\begin{tabular}{|c|c|c|}
\hline Variables & $\begin{array}{c}\text { Hazard ratio } \\
(95 \% \mathrm{Cl})\end{array}$ & $\mathbf{P}$ \\
\hline \multicolumn{3}{|l|}{ Univariate analysis } \\
\hline $\begin{array}{l}\text { Corticosteroid treatment duration, months } \\
\text { (continuous) }\end{array}$ & $1.02(0.995-1.04)$ & 0.196 \\
\hline$\geq 1$ acute cellular rejection episodes & $2.61(0.83-8.25)$ & 0.083 \\
\hline Colectomy pretransplant & $0.28(0.04-2.11)$ & 0.134 \\
\hline Cytomegalovirus mismatch & $2.48(0.89-6.90)$ & 0.083 \\
\hline $\begin{array}{l}\text { Presence of inflammatory bowel disease } \\
\text { pretransplant }\end{array}$ & $1.86(0.59-5.92)$ & 0.317 \\
\hline Age at transplant, years (continuous) & $0.98(0.94-1.02)$ & 0.347 \\
\hline Female sex & $0.55(0.12-2.45)$ & 0.397 \\
\hline Cyclosporine versus tacrolimus & $0.94(0.33-2.72)$ & 0.914 \\
\hline$\geq 2$ extended donor criteria & $1.36(0.46-3.98)$ & 0.586 \\
\hline \multicolumn{3}{|l|}{ Multivariate analysis } \\
\hline$\geq 1$ acute cellular rejection episodes & $5.69(1.26-25.82)$ & 0.013 \\
\hline Cytomegalovirus mismatch & $4.18(1.14-15.4)$ & 0.035 \\
\hline $\begin{array}{l}\text { Corticosteroid treatment duration, months } \\
\text { (continuous) }\end{array}$ & $1.02(0.994-1.05)$ & 0.179 \\
\hline Colectomy pretransplant & $0.32(0.04-2.51)$ & 0.207 \\
\hline
\end{tabular}

$(21,24,28,29)$. However, given the side effects associated with prolonged steroid use, its lack of efficacy as a maintenance therapy in the nontransplant population, and the small size and retrospective nature of existing studies, the current data cannot be used to justify long-term steroid use post-transplant. Because many programs are moving toward early steroid withdrawal, the impact of alternative immunosuppressive regimens on the control of post-transplant IBD requires further prospective evaluation. Azathioprine is known to be efficacious in the pretransplant setting and has also been suggested to have a role in the reduction of post-transplant IBD severity $(24,30)$. Although the use of azathioprine was not protective in our series, this may, in part, be attributed to the low dose (median $1.1 \mathrm{mg} / \mathrm{kg}$; range $0.9 \mathrm{mg} / \mathrm{kg}$ to $1.4 \mathrm{mg} / \mathrm{kg}$ ) that was used.

The rate of rPSC in our cohort $(25 \%)$ is within the range of $6 \%$ to $40 \%$ reported in the literature $(6,30,31)$ and is especially consistent with studies that used the strict Mayo clinic scoring system for the diagnosis of rPSC (10,32-34). At present, the literature remains unclear regarding risk factors for recurrent disease. Suggested predictors of recurrence have ranged from steroid therapy, ACR, steroid-resistant ACR, cholangiocarcinoma, sex mismatch, CMV mismatch, age at transplant, presence of co-existing IBD and the presence of an intact colon (31-38). ACR and CMV mismatch were independent predictors of rPSC in the present study. The association between ACR and rPSC was previously described $(32,36)$. Several hypotheses for this association have been generated including that particular patients may have a common predisposition to both ACR and rPSC due to an intense immune response or that damage to the biliary epithelium from ACR may facilitate further immunemediated ductal injury in the form of rPSC $(36,38,39)$. Using a multivariate Cox proportional hazards model, the current study found no association between the choice of post-transplant maintenance immunosuppression and $\mathrm{rPSC}-\mathrm{a}$ finding that is consistent with the literature. Although steroid therapy and rescue treatment for steroid-resistant rejection (muromonab,

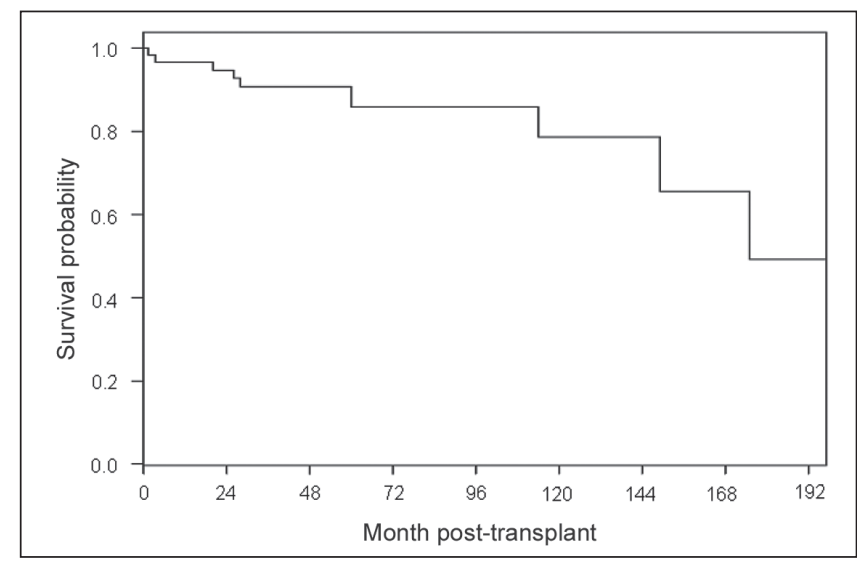

Figure 2) Survival curve of patients who received liver transplants for primary sclerosing cholangitis

antithymocyte globulin) have been found to be independent predictors of $\operatorname{rPSC}(34,37,38)$ in selected studies, these were not predictive of rPSC in the current series. In addition to the current study, CMV mismatch has been noted to be a predictor of rPSC in a single study (36). The potential explanation for CMV mismatch is unclear - the association of symptomatic CMV infection or CMV viremia post-transplant with rPSC was not evaluated in the current series. Because all patients in the current study who experienced rPSC had pre- or posttransplant IBD, with only one developing rPSC despite a pretransplant colectomy, we expected these may be important predictors of rPSC; however, they did not reach statistical significance. A larger study by Vera et al (31) suggested that an intact colon after transplant was an important predictor of rPSC. Therefore, it is possible that the lack of significance in the current series may be related to type-II statistical error. The use of a marginal donor graft was not a predictor of rPSC and, although not well studied, is consistent with the series in which cold ischemic time did not reach statistical significance as a predictor of rPSC (32-34).

The uncertainty regarding the optimal post-transplant immunosuppressive regimen for the control of both IBD and PSC, and the interaction of these two disease processes, therefore, remains unclear. Although it did not reach significance as a causative factor for rPSC in the current series, the median duration of steroid use was longer in patients with rPSC (nine months) than without (2.3 months). Steroid use has been associated with rPSC in other studies. Circa 2000, the use of steroids at our centre has been reserved for the treatment of ACR and for the management of UC flares. It is predictable that patients with pre- or post-transplant IBD require longer steroid treatment (median 6.5 months, range 0 to 12.5 months) than those without (median 0.1 months, range 0 to six months). Importantly, no patients without pre- or post-transplant IBD developed rPSC. What remains unclear from the available evidence is whether the problem triggering rPSC is excessive steroid use, the presence and severity of IBD, or the development of ACR. Confronted wih multiple confounding factors and the retrospective nature of the current trial, the impact of steroids on rPSC has not been established and will likely need to be investigated more closely in a prospective trial. 
The survival of patients who received liver transplants for PSC was excellent and not affected by rPSC or IBD. Although rates of development of post-transplant colon cancer have ranged from $1.5 \%$ to $35 \%(40-42)$, the $3 \%$ rate of colon cancer in the current series over a 68-month follow-up period is consistent with the most recent available evidence $(12,23,30,43)$. Given the increased risk of malignancy post-transplant, annual colonoscopy is strongly recommended in patients with PSC and UC (44).

Limitations of the current study include its retrospective design and small sample size. Six per cent of patients were excluded from the study because of missing data and it is possible that if all of these patients had rPSC, the results would have been altered. Furthermore, although stringent criteria were followed to make a diagnosis of rPSC, protocol liver biopsies and magnetic resonance imaging assessments are not standard practice at our centre and, therefore, some early cases of rPSC may have been missed. These numbers were expected to be minimal because patients with a persistent rise in their cholestatic liver enzymes are evaluated extensively. Finally, although we attempted to objectively evaluate the severity of IBD, given the retrospective nature of the study and the fluctuating course of IBD, some subjectivity in the determination of severity was unavoidable.

\section{CONCLUSION}

Although a significant proportion of our patients experienced worsening IBD after transplantation, the presence or severity of IBD did not influence the occurrence of rPSC or patient survival. ACR and CMV mismatch have been identified as risk factors for rPSC. The lack of rPSC in patients without pre- or post-transplant IBD and the development of rPSC in only one patient with a colectomy is interesting and consistent with the interaction of these two disease processes. Possibly due to type-II error, we have not been able to demonstrate either a significant beneficial or deleterious effect of steroid therapy in patients with PSC and UC. The impact of steroids and the ideal immunosuppressive regimen for the control of both IBD and PSC after transplantation require further examination in prospective studies.

ACKNOWLEDGEMENTS: The authors acknowledge Dr Kelly Burak for his assistance with data collection, and Dr Andrew Mason and Dr Klaus Gutfreund for their contributions to the manuscript.

\section{REFERENCES}

1. Gordon RD, Shaw BW Jr, Iwatsuki S, et al. Indications for liver transplantation in the cyclosporine era. Surg Clin North Am 1986;66:541-56.

2. Talwalkar JA, Lindor KD. Primary sclerosing cholangitis. Inflamm Bowel Dis 2005;11:62-72.

3. Portincasa P, Vacca M, Moschetta A, et al. Primary sclerosing cholangitis: Updates in diagnosis and therapy. World J Gastroenterol 2005;11:7-16.

4. Vacca M, Krawczyk M, Petruzzelli M, et al. Current treatments of primary sclerosing cholangitis. Curr Med Chem 2007;14:2081-94.

5. Goss JA, Shackleton CR, Farmer DG, et al. Orthotopic liver transplantation for primary sclerosing cholangitis. A 12-year single center experience. Ann Surg 1997;225:472-81; discussion 481-3.

6. Bjoro K, Brandsaeter B, Foss A, et al. Liver transplantation in primary sclerosing cholangitis. Semin Liver Dis 2006;26:69-79.
7. Saldeen K, Friman S, Olausson M, et al. Follow-up after liver transplantation for primary sclerosing cholangitis: Effects on survival, quality of life, and colitis. Scand J Gastroenterol $1999 ; 34: 535-40$

8. Khuroo MS, Al Ashgar H, Khuroo NS, et al. Biliary disease after liver transplantation: The experience of the King Faisal Specialist Hospital and Research Center, Riyadh. J Gastroenterol Hepatol 2005;20:217-28.

9. Sheng R, Campbell WL, Zajko AB, et al. Cholangiographic features of biliary strictures after liver transplantation for primary sclerosing cholangitis: Evidence of recurrent disease. Am J Roentgenol 1996;166:1109-13.

10. Graziadei IW, Wiesner RH, Batts KP, et al. Recurrence of primary sclerosing cholangitis following liver transplantation. Hepatology 1999;29:1050-6.

11. Banff schema for grading liver allograft rejection: An international consensus document. Hepatology 1997;25:658-63.

12. Befeler AS, Lissoos TW, Schiano TD, et al. Clinical course and management of inflammatory bowel disease after liver transplantation. Transplantation 1998;65:393-6.

13. Lucidi V, Lemye AC, Baire L, et al. Use of marginal donors for liver transplantation: A single-center experience within the Eurotransplant patient-driven allocation system. Transplant Proc 2007;39:2668-71.

14. Silberhumer GR, Pokorny H, Hetz H, et al. Combination of extended donor criteria and changes in the model for end-stage liver disease score predict patient survival and primary dysfunction in liver transplantation: A retrospective analysis. Transplantation 2007;83:588-92.

15. Schemmer P, Nickkholgh A, Hinz U, et al. Extended donor criteria have no negative impact on early outcome after liver transplantation: A single-center multivariate analysis. Transplant Proc 2007;39:529-34.

16. Clayton D, Hills M. Statistical Models in Epidemiology. Oxford: Oxford Science Publications, 1993.

17. Agresti A. Categorical Data Analysis. New York: John Wiley \& Sons, 1990.

18. Wiesner RH, Grambsch PM, Dickson ER, et al. Primary sclerosing cholangitis: Natural history, prognostic factors and survival analysis. Hepatology 1989;10:430-6.

19. Broome U, Olsson R, Loof L, et al. Natural history and prognostic factors in 305 Swedish patients with primary sclerosing cholangitis. Gut 1996;38:610-5.

20. Okolicsanyi L, Fabris L, Viaggi S, et al. Primary sclerosing cholangitis. Clinical presentation, natural history and prognostic variables: An Italian multicentre study. The Italian PSC study group. Eur J Gastroenterol Hepatol 1996;8:685-91.

21. Papatheodoridis GV, Hamilton M, Mistry PK, et al. Ulcerative colitis has an aggressive course after orthotopic liver transplantation for primary sclerosing cholangitis. Gut 1998;43:639-44.

22. van de Vrie W, de Man RA, van Buuren HR, et al. Inflammatory bowel disease and liver transplantation for primary sclerosing cholangitis. Eur J Gastroenterol Hepatol 2003;15:657-63.

23. Dvorchik I, Subotin M, Demetris AJ, et al. Effect of liver transplantation on inflammatory bowel disease in patients with primary sclerosing cholangitis. Hepatology 2002;35:380-4.

24. Ho GT, Seddon AJ, Therapondos G, et al. The clinical course of ulcerative colitis after orthotopic liver transplantation for primary sclerosing cholangitis: Further appraisal of immunosuppression post transplantation. Eur J Gastroenterol Hepatol 2005;17:1379-85.

25. Haagsma EB, Van Den Berg AP, Kleibeuker JH, et al. Inflammatory bowel disease after liver transplantation: The effect of different immunosuppressive regimens. Aliment Pharmacol Ther 2003;18:33-44.

26. Gavaler JS, Delemos B, Belle SH, et al. Ulcerative colitis disease activity as subjectively assessed by patient-completed questionnaires following orthotopic liver transplantation for sclerosing cholangitis. Dig Dis Sci 1991;36:321-8.

27. Shaked A, Colonna JO, Goldstein L, et al. The interrelation between sclerosing cholangitis and ulcerative colitis in patients undergoing liver transplantation. Ann Surg 1992;215:598-603. Discussion 604-5.

28. Miki C, Harrison JD, Gunson BK, et al. Inflammatory bowel disease in primary sclerosing cholangitis: An analysis of patients undergoing liver transplantation. Br J Surg 1995;82:1114-7. 
29. Gow PJ, Chapman RW. Liver transplantation for primary sclerosing cholangitis. Liver 2000;20:97-103.

30. Graziadei IW, Wiesner RH, Marotta PJ, et al. Long-term results of patients undergoing liver transplantation for primary sclerosing cholangitis. Hepatology 1999;30:1121-7.

31. Vera A, Moledina S, Gunson B, et al. Risk factors for recurrence of primary sclerosing cholangitis of liver allograft. Lancet 2002;360:1943-4

32. Alexander J, Lord JD, Yeh MM, et al. Risk factors for recurrence of primary sclerosing cholangitis after liver transplantation. Liver Transpl 2008;14:245-51.

33. Campsen J, Zimmerman MA, Trotter JF, et al. Clinically recurrent primary sclerosing cholangitis following liver transplantation: A time course. Liver Transpl 2008;14:181-5.

34. Cholongitas E, Shusang V, Papatheodoridis GV, et al. Risk factors for recurrence of primary sclerosing cholangitis after liver transplantation. Liver Transpl 2008;14:138-43.

35. Khettry U, Keaveny A, Goldar-Najafi A, et al. Liver transplantation for primary sclerosing cholangitis: A long-term clinicopathologic study. Hum Pathol 2003;34:1127-36.

36. Jeyarajah DR, Netto GJ, Lee SP, et al. Recurrent primary sclerosing cholangitis after orthotopic liver transplantation: Is chronic rejection part of the disease process? Transplantation 1998 27;66:1300-6.

37. Kugelmas M, Spiegelman P, Osgood MJ, et al. Different immunosuppressive regimens and recurrence of primary sclerosing cholangitis after liver transplantation. Liver Transpl 2003;9:727-32.

38. Brandsaeter B, Schrumpf E, Bentdal O, et al. Recurrent primary sclerosing cholangitis after liver transplantation: A magnetic resonance cholangiography study with analyses of predictive factors. Liver Transpl 2005;11:1361-9.

39. Charatcharoenwitthaya P, Lindor KD. Recurrence of primary sclerosing cholangitis: What do we learn from several transplant centers? Liver Transpl 2008;14:130-2.

40. Penn I. Cancer is a complication of severe immunosuppression. Surg Gynecol Obstet 1986;162:603-10.

41. Broome U, Lindberg G, Lofberg R. Primary sclerosing cholangitis in ulcerative colitis - a risk factor for the development of dysplasia and DNA aneuploidy? Gastroenterology 1992;102:1877-80.

42. Bleday R, Lee E, Jessurun J, et al. Increased risk of early colorectal neoplasms after hepatic transplant in patients with inflammatory bowel disease. Dis Colon Rectum 1993;36:908-12.

43. Loftus EV Jr, Aguilar HI, Sandborn WJ, et al. Risk of colorectal neoplasia in patients with primary sclerosing cholangitis and ulcerative colitis following orthotopic liver transplantation. Hepatology 1998;27:685-90.

44. Leddin D, Hunt R, Champion M, et al. Canadian Association of Gastroenterology and the Canadian Digestive Health Foundation: Guidelines on colon cancer screening. Can J Gastroenterol 2004;18:93-9. 


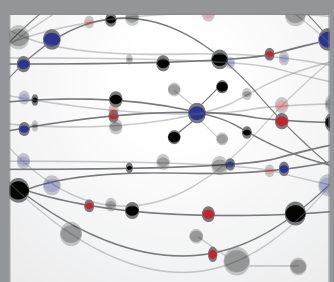

The Scientific World Journal
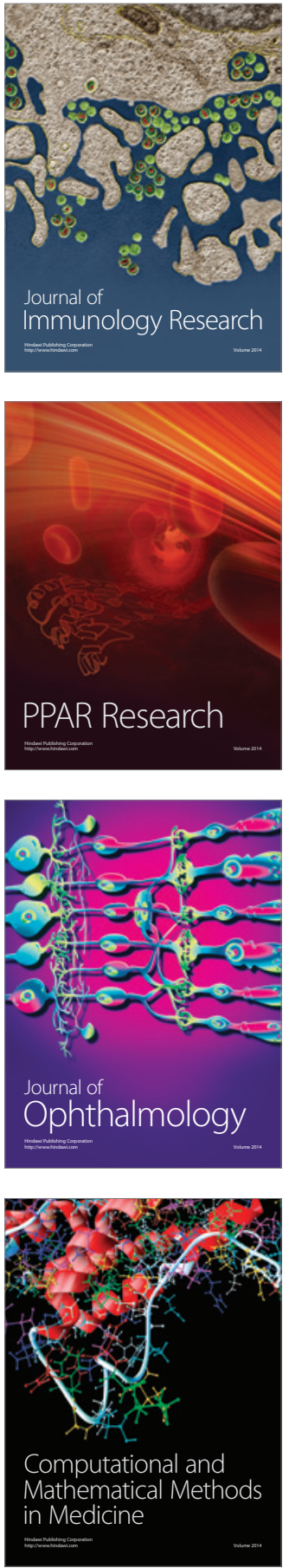

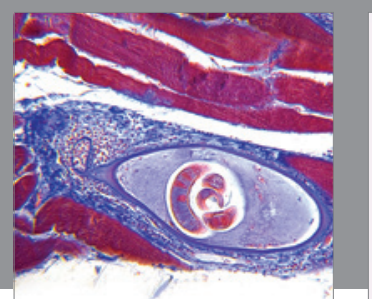

Gastroenterology Research and Practice

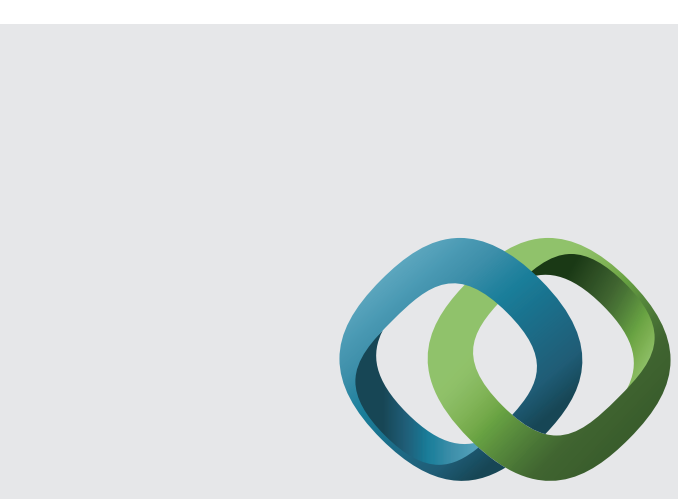

\section{Hindawi}

Submit your manuscripts at

http://www.hindawi.com
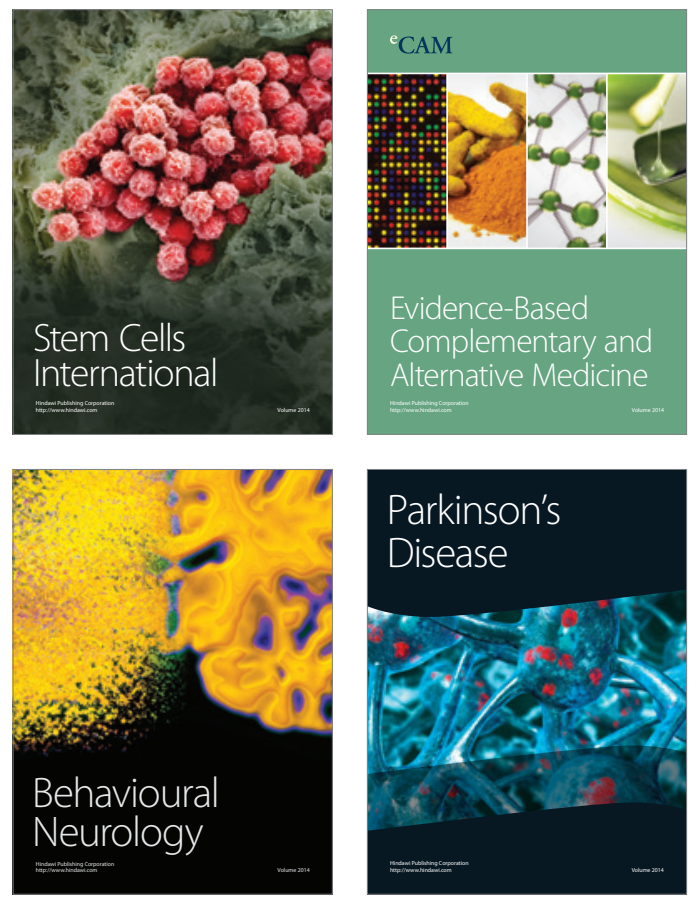
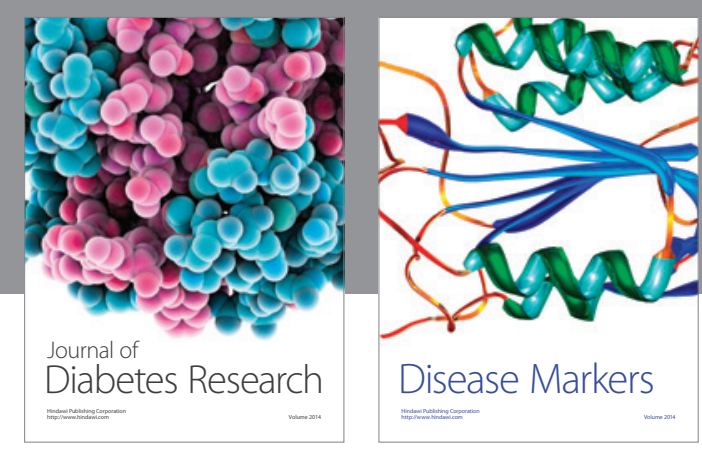

Disease Markers
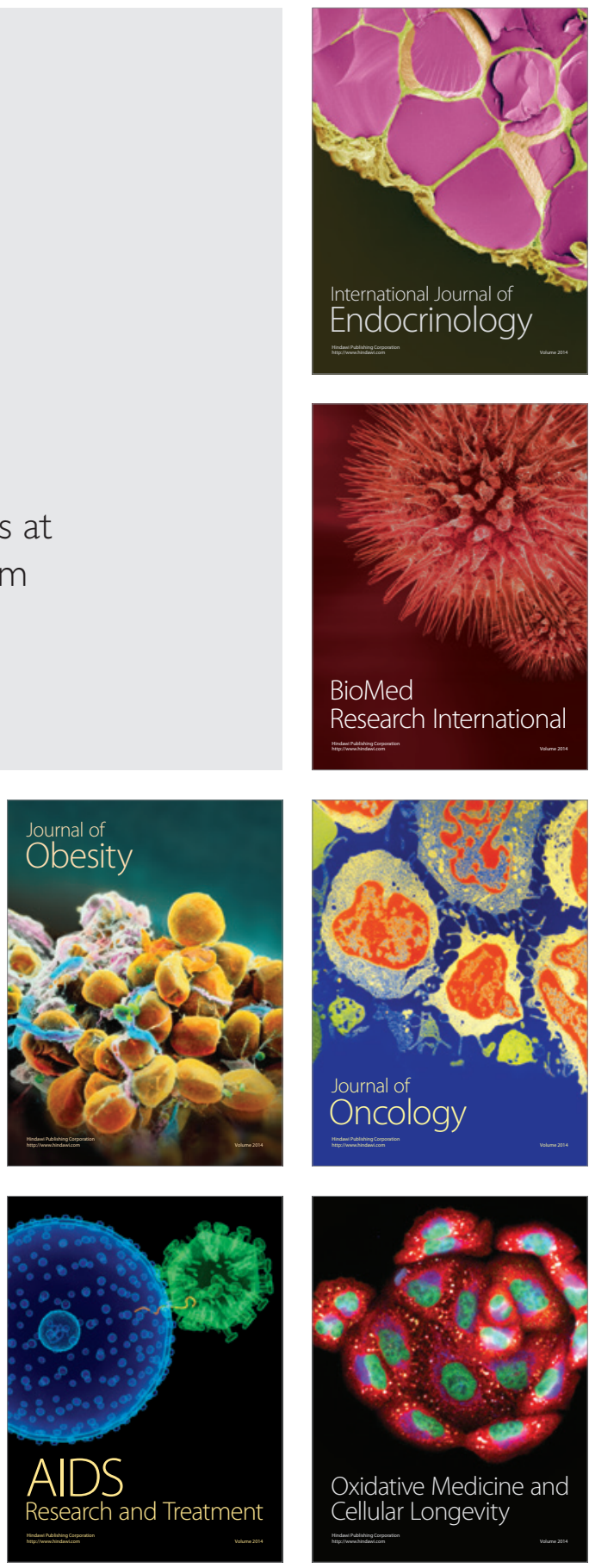